\title{
En ung jente med brudd i underekstremitetene og økende bevissthetspåvirkning
}

\author{
En ung jente ble innlagt med brudd i underekstremitetene etter \\ en trafikkulykke. Ved innleggelsen var hun våken, klar og orientert, \\ men i påvente av operasjon ble hun vanskeligere å få kontakt med. \\ Selv om det ikke var erkjent skade på luftveier eller lunger, hadde \\ hun flere oksygenmetningsfall og trengte tilførsel av oksygen.
}

En tidligere frisk jente i tenårene ble innlagt etter at hun som fotgjenger var blitt påkjørt av en personbil. Ved innleggelse hadde hun lett amnesi for hendelsen, men var våken, klar og orientert, Glascow Coma Scale (GCS) 15. Vitale variabler var normale - puls 95 slag/min, blodtrykk 123/81 mm Hg, respirasjonsfrekvens $14 / \mathrm{min}$ og oksygenmetning $98 \%$. Røntgenundersøkelse av underekstremitetene viste høyresidig femurskaftfraktur og venstresidig tibiaskaftfraktur. CT bekken viste fraktur $i$ venstre side av os sacrum og gjennom ramus superior og ramus inferior ossis pubis på samme side samt en beskjeden mengde fri væske $i$ det lille bekken. CT caput, thorax og abdomen avdekket ellers ingen skade.

Bekkenfrakturen ble klassifisert som en B2fraktur og trengte ikke operativ behandling. Derimot var det indikasjon for intern stabilisering av femur- og tibiaskaftfrakturene. Da hun var sirkulatorisk og respiratorisk stabil, ble det vurdert at hun kunne tåle behandling etter prinsippet «early total care», det vil si endelig kirurgisk stabilisering av alle frakturene tidlig i behandlingsfasen. Det ble planlagt operasjon med brotsjet margnagling av begge rørknoklene.

Mens hun ventet på operasjon, hadde hun smerter og fikk totalt $25 \mathrm{mg}$ ketobemidon intravenøst over 9-10 timer. Hun ble gradvis trettere og fikk etter hvert behov for tilførsel av oksygen. Ved preoperativ vurdering fikk anestesilege ikke adekvat kontakt. Før innledningen av narkosen kastet hun opp, og hun fulgte ikke instrukser om å legge hodet til siden. Episoden var ledsaget av et kortvarig oksygenmetningsfall til under $70 \%$.

Bevissthetspåvirkningen observert før operasjonen ble oppfattet som påfallende. Det ble vurdert om den kunne skyldes opioidpåvirkning. Årsaken til den varierende oksygenmetningen var også uklar. Hun hadde behov for tilførsel av oksygen, men ingen erkjent skade på luftveier eller lunger. I til- legg til mulig opioidpåvirkning ga episoden med oppkast mistanke om aspirasjon.

Pasienten ble operert i generell narkose med propofol og remifentanil intravenøst. Operasjonstiden for margnagling av de to rørknoklene var på omtrent seks timer. Ventileringen var uproblematisk peroperativt, med tilfredsstillende oksygenering. Grunnet blødning ble blodprosenten fulgt under operasjonen. Hb-verdien falt fra $11,3 \mathrm{~g} / 100 \mathrm{ml}$ til $8,6 \mathrm{~g} / 100 \mathrm{ml}$, og pasienten fikk til sammen fire poser SAGMAN-blod og plasma under operasjonen. Postoperativt fikk hun standard tromboseprofylakse med $40 \mathrm{mg}$ lavmolekylært heparin (enoksaparin) daglig.

Etter at hun kom på intensivavdelingen, var det et fall i oksygenmetning til $50 \%$. Det ble derfor startet kontinuerlig overtrykksbehandling (CPAP) på maske. Postoperativt våknet hun ikke. Ved undersøkelse neste formiddag kunne øyeåpning ikke fremkalles. Ved sterke smertestimuli reagerte hun med ikke-målrettede fleksjonsbevegelser i overekstremitetene. I tillegg hadde hun store pupiller, blikkdeviasjon mot venstre og vedvarende hodedreining til samme side. CPAP-masken ble forsøksvis fjernet, men hun falt umiddelbart i oksygenmetning og klarte ikke å holde frie luftveier.

Medikamentpåvirkning ble overveid som årsak til manglende oppvåkning, men avskrevet fordi preparatene som ble anvendt under narkosen, hadde kort halveringstid. Ikkeerkjent cerebral skade ble vurdert - f.eks. uoppdaget kraniefraktur med økende symptomer som følge av epiduralblødning. Bakgrunnen for respirasjonspåvirkningen var også uavklart. En aspirasjonspneumoni etter episoden med oppkast ble ansett som sannsynlig. Utvikling av akutt lungesviktsyndrom (acute respiratory distress syndrom, ARDS) kunne også være en mulighet.

CT caput ble gjentatt og var fortsatt uten patologiske funn. Supplerende MR-undersøkelse var ønskelig, men ikke umiddelbart tilgjengelig. Røntgen thorax, frontbilde, var
Simone Goa Diab

simone.diab@vestreviken.no

Barneavdelingen

\author{
Marianne Oroszko Haakonsen \\ Lars Borgen \\ Avdeling for bildediagnostikk \\ Drammen sykehus
}

Elisabeth Ellingsen Husebye

Ortopedisk avdeling

Oslo universitetssykehus, Ullevål 

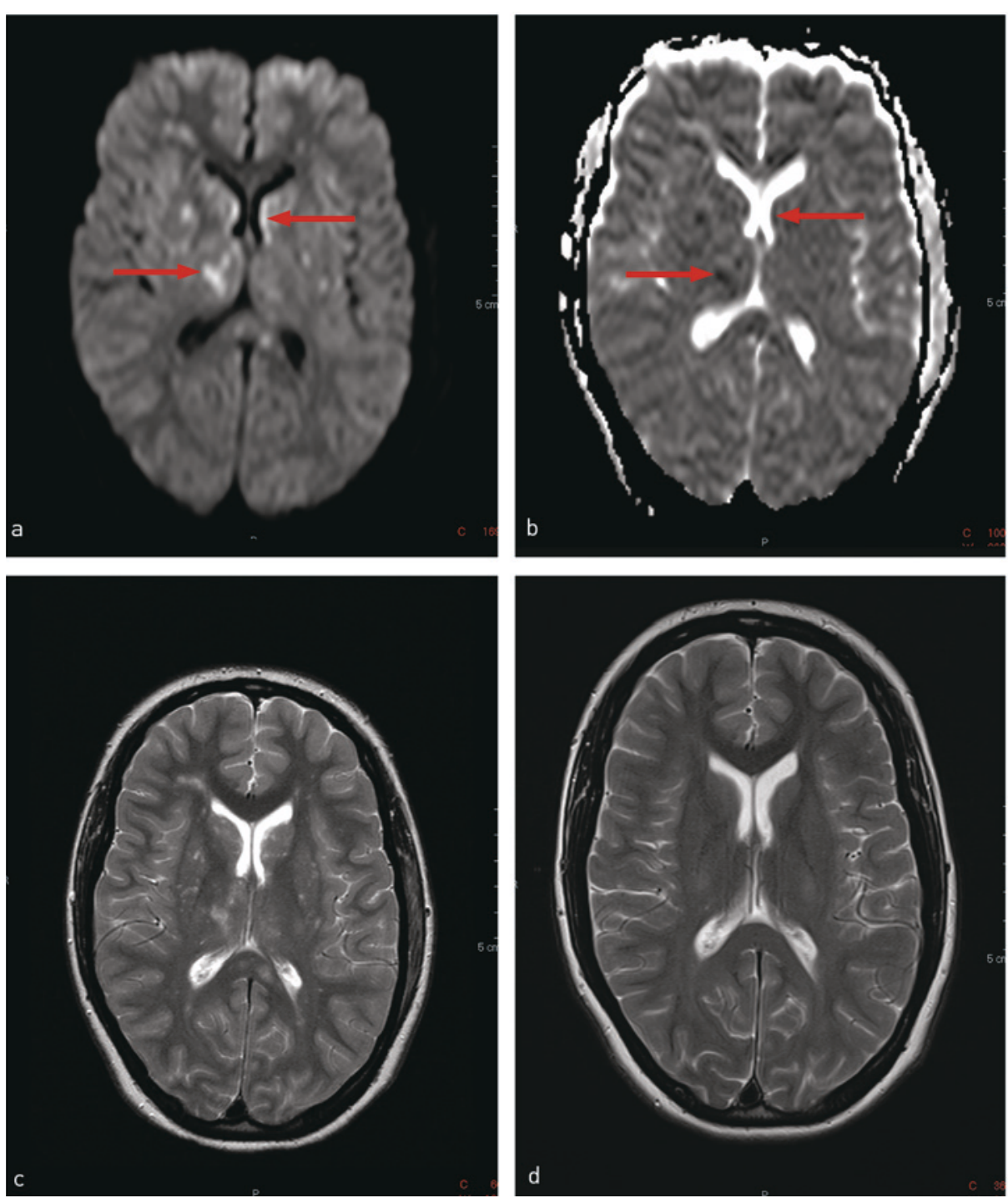

Figur 1 MR caput. a, b) Diffusjonsserien tatt tre døgn etter skadetidspunktet. a) Lesjoner med høyt signal er distribuert nokså symmetrisk i hvit substans. De av lesjonene som samtidig har lavt signal på b, representerer iskemi (piler). c, d) T2-vektede bilder i samme nivå fra henholdsvis diagnosetidspunktet og to år etter skaden. Sistnevnte viser regresjon av forandringene

uten tegn til lungefortetninger eller pneumothorax.

CT-undersøkelsen ble beskrevet som negativ, med forbehold om at cerebral CT ikke kan utelukke beskjeden diffus aksonal skade eller små/ tidlige tromboemboliske infarkter. Ut fra skademekanismen var diffus aksonal skade aktuell differensialdiagnose. Dette er tidligere beskrevet hos pasienter med GCS-skår på 15 (1). Et mildt tilfelle kunne imidlertid ikke forklare den alvorlige utviklingen av symptomene.

Paradoks embolisering av fett eller trombe ble vurdert. Risikoen for trombose var økt som følge av endringer i koagulabilitet og homøostase i forbindelse med traume og operasjon (2). Men siden symptomene viste seg allerede få timer etter skadetidspunktet, ble sannsynligheten for tromboembolisme likevel vurdert som beskjeden. Ved nevrologisk tilsyn ble det heller ikke funnet tegn til hjernestammeaffeksjon eller fokalnevrologiske utfall, som forventet ved et cerebralt infarkt.

Fraværet av lungefortetninger ved gjentatte røntgenundersøkelser utelukket akutt lungesviktsyndrom og aspirasjonspneumoni som årsak til respirasjonspåvirkningen. $\mathrm{Mu}-$ ligheten for pulmonal tromboembolisme ble diskutert, men den gradvise utviklingen av symptomer over få timers immobiliseringstid talte imot. Det fantes heller ingen tegn til dyp venøs trombose i underekstremitetene. Allerede ved innkomst var D-dimer forhøyet til $15 \mathrm{mg} / 1(<0,3 \mathrm{mg} / \mathrm{l})$, hvilket ble tilskrevet det initiale traumet. Det ble derfor vurdert som lite hensiktsmessig å gjenta prøven i diagnostisk øyemed.

To døgn etter skaden var det fortsatt ikke mulig å få kontakt med pasienten. Nevrokirur- gisk vaktteam ble konsultert og anbefalte utredning med tanke på cerebral sirkulasjonsforstyrrelse, herunder disseksjon av halskar. Det ble utført CT angiografi av cervikale og cerebrale kar, men intet patologisk ble avdekket. Samme dag ble det observert små prikker i huden på pasientens bryst og mage. Blodprøver viste stigende CRP-nivå, fra $2 \mathrm{mg} / \mathrm{l}$ til 148 $\mathrm{mg} / \mathrm{l} /<8 \mathrm{mg} / \mathrm{ll}$, normalisering av leukocyttall, fra $16,0 \cdot 10^{9} / \mathrm{l}$ til $7,9 \cdot 10^{9} / \mathrm{l}\left(3,5-11,0 \cdot 10^{\%} / \mathrm{l}\right)$, fallende trombocyttall, fra $176 \cdot 10^{9} / \mathrm{l}$ til $55 \cdot 10^{9} / \mathrm{l}\left(145-390 \cdot 10^{\%} / \mathrm{l}\right)$, og vedvarende lavt hemoglobinnivå på 9,1 g/100 ml (11,7-15,3 g/ $100 \mathrm{ml}$ på tross av transfusjon.

Laboratoriefunnene ble tolket som en inflammatorisk respons på traumet og operasjonen. Det var ingen sikre holdepunkter for infeksjon, men med tanke på et ikke-erkjent fokus ble det likevel startet intravenøs antibiotikabehandling. Pasienten ble drøftet tverrfaglig mellom ortoped, anestesilege og nevrolog. Det fantes nå flere kliniske og laboratoriemessige holdepunkter for fettembolismesyndrom, og det ble besluttet å starte høydosebehandling med metylprednisolon.

Det ble startet intravenøs behandling med metylprednisolon $1 \mathrm{~g} \times 4$ daglig samt cefuroksim. Dagen etter, tre døgn etter skadetidspunktet, var symptombildet uendret, og det ble besluttet å utføre EEG og MR caput ut fra mistanken om fettembolismesyndrom. EEG viste et betydelig patologisk, generelt for langsomt kurvebilde. MR cerebrum viste multiple små områder med restriktiv diffusjon, forenlig med fersk iskemi (fig 1). Områdene var beliggende nokså symmetrisk og hovedsakelig sentralt $i$ supratentoriell hvit substans. Enkelte tilsvarende lesjoner ble påvist $i$ begge cerebellarhemisfærer. Funnene, både ved EEG og $M R$, kunne passe med fettembolismesyndrom. Etter anbefaling fra regionalt traumesykehus ble pasienten overflyttet for diagnostisk avklaring og intrakranial trykkmåling.

MR-undersøkelsen ble gjentatt, med uendrede funn. Det intrakraniale trykket var normalt. Utredning med transøsofageal ekkokardiografi viste normale forhold $i$ basalsituasjonen, men ved boblekontrastforsøk fantes kontrastovergang fra høyre til venstre atrium etter fire slag. Funnet var forenlig med persisterende foramen ovale. Diagnosen fettembolismesyndrom ble fastholdt, og det ble ikke iverksatt behandlingsmessige tiltak utover understøttende behandling.

Atte dager etter skaden lot pasienten seg vekke, og etter ytterligere to dager ble hun utskrevet til rehabilitering. Hun hadde da lett redusert kraft $i$ høyre overekstremitet og redusert visus. Nevropsykologisk utredning viste god kognitiv funksjon, men kapasitetsproblemer og lett økt trettbarhet. På samtlige 
områder ble hun gradvis bedre under rehabiliteringsoppholdet. Kraften i høyre overekstremitet normaliserte seg.

Pasienten ble utskrevet til hjemmet knapt to og en halv måned etter skadetidspunktet. Hun gjenopptok vanlig skolegang og fullførte skoleåret. Kontroll med MR caput to år etter skaden viste tilnærmet normalisering av forandringene, det var kun beskjedne gjenværende signalavvik.

\section{Diskusjon}

Fettembolismesyndrom (FES) er en potensiell komplikasjon ved skjelettraumer. Risikoen for tilstanden øker ved konservativ eller forsinket behandling av rørknokkelfrakturer og ved multiple frakturer (3-7). I tillegg er syndromet assosiert med ortopedisk protesekirurgi og margnagling av femur, særlig ved teknikker som medfører høyt intramedullært trykk (8). Eksempler på langt sjeldnere årsaker til fettembolismesyndrom er massiv bløtvevsskade, forbrenninger og beinmargsbiopsi (9).

Tilstanden er generelt hyppigere hos unge voksne enn i andre aldersgrupper $(3,6,7)$. Den faktiske insidensen er ukjent, da milde tilfeller sannsynlig er underdiagnostisert. I studier fra 1970- og 80-årene er det anslått at de diagnostiske kriteriene er oppfylt hos $3,5 \%$ av pasientene med enkeltstående konservativt behandlede rørknokkelfrakturer og hos opp mot $33 \%$ av dem med større traumer $(3,4)$. I nyere studier angis en lavere insidens, hvilket tilskrives fremskritt innen intensivbehandling samt innføring av andre begreper, som systemisk inflammatorisk respons-syndrom (systemic inflammatoric response syndrome, SIRS) og multiorgansvikt (MOF), som tidligere kan ha blitt karakterisert som fettembolismesyndrom $(4$, $5,10)$. I en studie fra 2011, der 1692 pasienter med fraktur av lange rørknokler og bekken etter ulykke var inkludert, fant man en insidens på $0,7 \%$ (11).

Fettembolismesyndrom er i utgangspunktet en klinisk diagnose. Manifestasjonene utgjøres særlig av triaden cerebrale symptomer (80-86\% av pasientene), lungedysfunksjon $(75 \%)$ og petekkier $(20-57 \%)(4-7,12)$. Utslettet er å regne som patognomonisk (11, 13). Diagnostisk er Gurd \& Wilsons kriterier mest anvendt (12). Diagnosen stilles da ved tilstedeværelse av minst ett av tre hovedkriterier, fire av åtte bikriterier samt fettmakroglobulinemi (økt plasmanivå av makroglobuliner bestående av fett) (tab 1). Symptomene oppstår vanligvis 12-72 timer etter et traume, men kan inntre allerede etter 4-6 timer $(4,12)$.

Den patofysiologiske forklaringen er omdiskutert, og det finnes to hovedteorier. Ifølge den mekaniske teorien blir fettdråper fra beinmargen frigjort $i$ det venøse systemet og transportert til høyre hjertehalvdel og lungekretsløpet $(4,6,7)$. I lungene vil fettdråpene obstruere mikrovaskulaturen og medføre lokal iskemi og inflammasjon. Dersom den mekaniske obstruksjonen er tilstrekkelig, utvikles pulmonal hypertensjon og belastning av høyre ventrikkel. I noen tilfeller vil fettdråpene passere via intrakardiale eller pulmonale høyre-venstre-shunter til det systemiske kretsløp og affisere andre organer, for eksempel hjernen (såkalt paradoksembolisme) (14-17).

Den biokjemiske teorien bygger på en antakelse om at et traume induserer lipolyse av fett til frie fettsyrer og glyserol $(4,6,7$, 12). Hvorvidt fettet kommer fra beinmargen eller sirkulerende fettmolekyler, er omstridt. Likeledes er det uklart om lipolysen skjer systemisk, på frakturstedet eller i lungene. Det er imidlertid enighet om at sirkulerende frie fettsyrer i høye konsentrasjoner forårsaker inflammasjon, endotelskade og trombedanning. I motsetning til andre emboliske hendelser er den vaskulære okklusjonen ofte inkomplett eller forbigående ved fettembolisering. Dette kan være til diagnostisk hjelp.

Vår pasient hadde multiple frakturer, gjennomgikk operasjon med margnagling av lange rørknokler og hadde et persisterende foramen ovale. Ut fra den mekaniske teorien var hun således i risiko for cerebral embolisering. Siden hun initialt var sirkulatorisk og respiratorisk stabil, ble det vurdert at hun kunne tåle behandling av bruddene etter prinsippet «early total care».

Påvirkningen av respirasjon og bevissthet, som kom preoperativt, ble tilskrevet opiodpåvirkning og aspirasjon. Beslutningen om operasjon ble derfor fastholdt. Hvorvidt en behandlingsstrategi med midlertidig ekstern fiksasjon av frakturene (etter prinsippet «damage control orthopedic») kunne forhindret fettembolismesyndromet, kan det spekuleres i. Retrospektivt vurderer vi det imidlertid som sannsynlig at pasienten hadde symptomer på fettembolismesyndrom allerede før operasjonen.

Når det gjelder ekkoundersøkelsen, som ble gjort under pågående respiratorbehandling, fantes høyre-venstre-shunting over atrieseptum. Enhver økning av pulmonaltrykket, f.eks. ved hoste, mekanisk ventilering eller pulmonale emboluser, kan ha medført en funksjonell åpning av persisterende foramen ovale og paradoks embolisering (17). I hvilken grad denne shuntingen bidrar til alvorlighetsgraden ved fettembolismesyndrom er omdiskutert (15). I en autopsistudie publisert i 2012 var det ingen signifikant forskjell mellom pasienter med og uten persisterende foramen ovale. Dette ble tatt til inntekt for at åpning av venoarterielle shunter i lungene har større betydning.

Affeksjon av lungegebetet er ofte det første som gir symptomer og funn, typisk i form av
Tabell 1 Diagnostiske kriterier etter Gurd \& Wilson (12). Diagnosen fettembolismesyn drom stilles ved tilstedeværelse av minst ett hovedkriterium og fire bikriterier samt fettmakroglobulinemi

\begin{tabular}{ll} 
Hovedkriterier & Cerebrale symptomer \\
& Lungedysfunksjon \\
& Petekkier \\
Bikriterier & Pyreksi \\
& Takykardi \\
& Retinale endringer \\
& Icterus \\
& Renale endringer \\
& Trombocytopeni \\
& Høy senkningsreaksjon \\
& Anemi \\
\hline Fettmakro- & \\
\hline globulinemi & \\
\hline
\end{tabular}

dyspné, takypné og hypoksemi. Vår pasient hadde flere episoder med hypoksemi. Den kliniske presentasjonen av lungeaffeksjonen er uspesifikk og vil kunne forveksles med pneumothorax, pneumoni, stuvning/lungeødem av annen årsak og eventuelt tromboembolisme. Ved sent innsettende fettembolismesyndrom kan det være utfordrende å skille tilstanden fra tromboembolisme (6). Pulmonale fettemboluser kan hos noen pasienter gi en alvorlig respirasjonsinsuffisiens og anses som en av årsakene til akutt lungesviktsyndrom (10).

Hos vår pasient var røntgen thorax negativ, men undersøkelsen vil ofte vise spredte diffuse fortetninger - «snø» (snow storm apperance) - over begge lungefeltene $(4,6$, 12). CT thorax vil ofte vise mattglassfortetninger, noduler og/eller fortykkede interstitielle septa (18). Graden av røntgen-/CTfunn kan variere, og i mer uttalte tilfeller påvises konsoliderende fortetninger. I likhet med de kliniske funnene er de bildediagnostiske funnene uspesifikke og kan forveksles med flere av de overnevnte tilstander.

Det petekkiale utslettet er typisk lokalisert på halsen, overkroppen og $\mathrm{i}$ ansiktet (11-13), noe som kan være til diagnostisk hjelp. Enkelte hevder at distribusjonen er et resultat av at fettpartiklene i aortabuen «flyter som olje i vann» og dermed transporteres til ikkedeklive områder $(4,6,7,12)$. I hvilken grad utslettet kan tilskrives henholdsvis mikrovaskulær okklusjon av dermale kapillærer og trombocytopeni med disseminert intravaskulær koagulasjon (DIC) er likevel uklart.

Den cerebrale påvirkningen kan variere og vise seg som hodepine, akutt konfusjon, fokal- 
nevrologiske utfall, kramper og koma. Som hos vår pasient kan en nærliggende differensialdiagnose være ikke-erkjent cerebral skade. Når det gjelder påvisning av de cerebrale lesjonene, har det vist seg at CT-undersøkelse er inadekvat. Som i dette tilfellet vil undersøkelsen ofte være negativ på tross av tilstedeværende nevrologiske symptomer $(19,20)$. I sjeldne tilfeller vil CT vise diffust ødem eller enkelte hypodense fokuser $(14,19-21)$. Disse funnene er imidlertid uspesifikke, og det er ofte behov for ytterligere utredning med MR.

MR-undersøkelse kan bidra til å skille fettembolismesyndrom både fra direkte traumatiske skader og fra traumerelaterte komplikasjoner som infarkt og encefalopati. Diffusjons-, T2- og FLAIR (Fluid-Attenuated Inversion Recovery)-sekvensene vil typisk vise multiple høysignalfokuser symmetrisk distribuert i hvit substans, både subkortikalt og periventrikulært. Forandringene er beskrevet som et karakteristisk stjernemønster (starfield pattern) $(20,21)$.

Signalforandringene på de T2-vektede seriene kan tilskrives cytotokisk ødem, assosiert med iskemi, og/eller vasogent ødem, som følge av den toksiske effekt av frie fettsyrer. Diffusjonsserien bidrar til å identifisere de lesjonene som representerer iskemi. Iskemiforandringer finnes også ved akutt tromboembolisme, men tilstandene kan som regel skilles på bakgrunn av distribusjonsmønsteret. Tromboembolismer er oftest unilaterale og unifokale. Lokalisasjonen av forandringene ved fettembolismesyndrom tilsvarer derimot forsyningsområdene til de terminale grenene av intracerebrale arterier på begge sider.

De terapeutiske mulighetene er begrenset. Oppmerksomheten bør rettes mot forebyggende og understøttende tiltak som stabilisering av frakturer, forebygging av hypovolemisk sjokk, ivaretakelse av vevsoksygenering samt smertelindring $(6,12)$. Medikamentell behandling er kontroversielt. Steroider kan tilsynelatende redusere nivået av sirkulerende frie fettsyrer og hemme den inflammatoriske kaskaden i tidlige stadier av syndromet (6). En metaanalyse fra 2006 antyder at administrasjon av kortikosteroider ved fraktur av lange rørknokler gir en reduksjon i forekomsten av fettembolismesyndrom. Analysen er dog basert på hovedsakelig eldre studier av lav kvalitet, og forfatterne anbefaler større randomiserte studier før en eventuell endring av praksis (22).

Mortalitetsraten ble i studier fra 1960- og 70 -årene angitt til $10-20 \%(5,22)$. I senere studier har den vært lavere og er blitt anslått til opp mot $7-8 \%(5,11)$. Alvorlige tilfeller kan fremstå som progredierende respirasjonssvikt og akutt cor pulmonale og lede til døden innen få timer $(9,11,15)$. Ved ikke-letale tilfeller oppnås ofte full klinisk restitusjon (11).

Lungefunksjonen er vanligvis gjenvunnet innen en uke (4). Cerebrale lesjoner utløst av iskemi kan dog gi permanente patologiske endringer som gliose eller væskefylte hulrom og føre til vedvarende endringer i personlighet og kognitiv funksjon $(4,9)$. Flere har antydet en korrelasjon mellom mengden av iskemisk pregede forandringer på $\mathrm{MR}$ og prognosen $(19,23)$. Lette iskemiforandringer samt forandringene utløst av den direkte toksiske effekten av frie fettsyrer tenderer derimot til å regrediere fullstendig.

Hos vår pasient ble diagnosen stilt først tre dager etter symptomdebut. Vi tror ikke dette har hatt betydning for verken behandling eller prognose, da hun i kraft av å være intensivpasient allerede fikk understøttende behandling. En tidlig diagnose er likevel å foretrekke - både for å unngå overflødige undersøkelser hos en marginal pasient og for å skåne de pårørende for unødvendig uvisshet.

\section{Konklusjon}

$\mathrm{Vi}$ beskriver et pasientforløp der diagnosen fettembolismesyndrom ble stilt med en viss forsinkelse - selv ved tilstedeværelse av syndromets tre kliniske hovedkriterier: cerebral påvirkning, lungedysfunksjon og petekkier. Utfordringen er muligens at de ulike manifestasjonene forveksles med symptomer assosiert med andre, hyppigere forekommende tilstander.

Diagnostisering av tilstanden krever klinisk mistanke samt utelukking av andre, behandlingskrevende tilstander. Medikamentell behandling er kontroversielt, og oppmerksomheten bør rettes mot forebyggende og understøttende tiltak.

Pasienten og pasientens mor har gitt samtykke til at artikkelen blir publisert.

\section{Simone Goa Diab (f. 1979)}

er lege i spesialisering i pediatri og konstituert overlege. Hun har to års erfaring i radiologi.

Forfatter har fylt ut ICMJE-skjemaet og oppgir ingen interessekonflikter.

\section{Marianne Oroszko Haakonsen (f. 1961)}

er spesialist i radiologi og overlege ved MR-seksjonen.

Forfatter har fylt ut ICMJE-skjemaet og oppgir ingen interessekonflikter.

\section{Lars Borgen (f. 1970)}

er ph.d. og spesialist i radiologi. Han er overlege, jobber med intervensjonsradiologi og er førsteamanuensis ved Avdeling for helsefag, Høgskolen i Buskerud.

Forfatter har fylt ut ICMJE-skjemaet og oppgir ingen interessekonflikter.

\section{Elisabeth Ellingsen Husebye (f. 1966)}

er ph.d., spesialist i ortopedisk kirurgi og overlege. Hun er styremedlem i NOFAF.
Forfatter har fylt ut ICMJE-skjemaet og oppgir ingen interessekonflikter.

\section{Litteratur}

1. Schreiber MA. Coagulopathy in the trauma patient. Curr Opin Crit Care 2005; 11: 590-7

2. Vik A, Kvistad KA, Skandsen T et al. Diffus aksonal skade ved hodetraume. Tidsskr Nor Lægeforen 2006: 126: $2940-4$

3. ten Duis HJ, Nijsten MW, Klasen HJ et al. Fat embolism in patients with an isolated fracture of the femoral shaft. J Trauma 1988; 28: 383-90.

4. ten Duis HJ. The fat embolism syndrome. Injury 1997: 28: 77-85.

5. Bulger EM, Smith DG, Maier RV et al. Fat embolism syndrome. A 10-year review. Arch Surg 1997 132: 435-9

6. Parisi DM, Koval K, Egol K. Fat embolism syndrome. Am J Orthop (Belle Mead NJ) 2002; 31: 507-12.

7. Gossling HR, Pellegrini VD Jr. Fat embolism syndrome: a review of the pathophysiology and physiological basis of treatment. Clin Orthop Relat Res 1982; nr. 165: 68-82

8. Högel F, Gerlach UV, Südkamp NP et al. Pulmonary fat embolism after reamed and unreamed nailing of femoral fractures. Injury 2010; 41: 1317-22.

9. Shaikh N. Emergency management of fat embolism syndrome. J Emerg Trauma Shock 2009; 2: 29-33.

10. Husebye EE, Lyberg T, Røise O. Bone marrow fat in the circulation: clinical entities and pathophysiological mechanisms. Injury 2006: 37 (suppl 4): S8-18.

11. Gupta B, D'souza N, Sawhney C et al. Analyzing fat embolism syndrome in trauma patients at AlIMS Apex Trauma Center, New Delhi, India. J Emerg Trauma Shock 2011; 4: 337-41

12. Gurd AR, Wilson RI. The fat embolism syndrome. J Bone Joint Surg Br 1974; 56B: 408-16.

13. Tachakra SS. Distribution of skin petechiae in fat embolism rash. Lancet 1976; 1: 284-5.

14. Shaikh N, Parchani A, Bhat V et al. Fat embolism syndrome: clinical and imaging considerations: case report and review of literature. Indian J Crit Care Med 2008; 12: 32-6

15. Nikolić S, Zivković $V$, Babić $D$ et al. Systemic fat embolism and the patent foramen ovale-a prospective autopsy study. Injury 2012; 43: 608-12.

16. Cetinkaya A, Naess CE, Rønning OM et al. En 47 å gammel kvinne med akutt forvirring etter innsetting av total hofteprotese. Tidsskr Nor Legeforen 2008: 128: 831-3.

17. Pell ACH, Hughes D, Keating J et al. Brief report fulminating fat embolism syndrome caused by paradoxical embolism through a patent foramen ovale. N Engl J Med 1993; 329: 926-9.

18. Malagari K, Economopoulos N, Stoupis C et al. High-resolution CT findings in mild pulmonary fat embolism. Chest 2003; 123: 1196-201.

19. Takahashi M, Suzuki R, Osakabe Y et al. Magnetic resonance imaging findings in cerebral fat embolism: correlation with clinical manifestations. J Trauma 1999; 46: 324-7

20. Chen JJ, Ha JC, Mirvis SE. MR imaging of the brain in fat embolism syndrome. Emerg Radiol 2008; 15: 187-92.

21. Parizel PM, Demey HE, Veeckmans G et al. Early diagnosis of cerebral fat embolism syndrome by diffusion-weighted MRI (starfield pattern). Stroke 2001: 32: 2942-4.

22. Bederman SS, Bhandari M, McKee MD et al. Do corticosteroids reduce the risk of fat embolism syndrome in patients with long-bone fractures? A meta-analysis. Can J Surg 2009; 52: 386-93.

23. Pfeffer $G$, Heran MKS. Restricted diffusion and poor clinical outcome in cerebral fat embolism syndrome. Can J Neurol Sci 2010; 37: 128-30. 